\title{
APPLICATION OF THE FINITE ELEMENT METHOD IN THE MILLING PROCESS STABILITY DIAGNOSIS
}

\author{
Pawee Dunaj, Krzysztof Marchelek, Marcin Chodźko \\ West Pomeranian University of Technology, Institute of Manufacturing Engineering, Szczecin, Poland \\ e-mail: pawel.dunaj@zut.edu.pl; krzysztof.marchelek@zut.edu.pl; marcin.chodzko@zut.edu.pl
}

\begin{abstract}
The article presents results of both experimental and FEM model-based investigations on chatter phenomena that occur in the end milling process. On the basis of chatter symptoms observed during machining, the mechanism of its occurrence has been identified. Then, a FEM model has been built to indicate machine tool elements responsible for loss of stability. Afterwards, experimental modal analysis has been conducted in order to validate the FEM model. Finally, on the basis of the validated model, the structural changes have been proposed and applied in the real object resulting in increased stability.
\end{abstract}

Keywords: chatter, finite element modelling, modal analysis, machine tool

\section{Introduction}

Complex mechanical engineering products are developed by gradually modifying their structure and parameters (e.g. by introducing innovative materials). In the case of production machinery, this is associated with increasing requirements in terms of accuracy, repeatability and efficiency, and the need for the lowest possible energy consumption and generated noise. Even small modifications of the machine structure or parameters can significantly affect its properties (Chodźko and Pajor, 2016; Dunaj and Chodźko, 2017; Pulikowski et al., 2017). If these modifications are not pre-tested using models, it is highly likely to obtain a different effect than the desired and, as a result, reduction of the usefulness of the machine (Altintas, 2012).

In the physical sense, the machine-holder-workpiece-tool system is a mass-spring-damper system with all the features of an oscillating system. Loads accompanying the cutting process vary with time and cause disturbances in the motion of such a system, manifested as vibrations of various nature (Marchelek et al., 2002; Tomków, 1997). Self-excited vibrations accompanying the cutting process are particularly dangerous (Gradišek, 2005; Tlusty, 1983).

The mechanism behind the loss of machining stability usually has a complex nature. It is usually ascribed to (i) regenerative chatter which occurs when cuts overlap and the cut produced at a time $t$ leaves small waves in the material that are regenerated during each subsequent pass of the tool (Dombovari et al., 2011; Faassen et al., 2003), (ii) mode coupling resulting from unfavorable coupling of mass-spring-damper properties (Jafarzadeh and Movahhedy, 2017; Tlusty and Polacek, 1963), as well as (iii) vibrations caused by frictional chatter (Rusinek et al., 2014; Wiercigroch and Krivtsov, 2001). Regardless of the cause, the stability loss results in a significant increase in the relative amplitude of vibrations of the tool and workpiece, which have a negative impact on the quality of the machining and durability of the tool and the entire machine.

Many works have been devoted to the issues of detection (Berczyński et al., 2001; Kuljanic et al., 2008; Liu et al., 2018; Yao et al., 2010; Jasiewicz and Powałka, 2018b), identification (Cao et al., 2013; Rusinek et al., 2015) and counteracting this phenomenon (Hayasaka et al., 2017; Munoa et al., 2016; Suzuki et al., 2016). Researchers mention the high importance of developing a 
reliable model, validated based on the results of experimental research, with particular emphasis on the representation of machine tool dynamics.

Many methods have been developed for the modelling of dynamical properties of machine tools, including finite elements (Zienkiewicz and Taylor, 1997), rigid finite elements (Wittbrodt et al., 2007) and hybrid methods (Jastrzębski, 2008; Zaeh et al., 2004; Jasiewicz and Powałka, 2018a). They are based on replacing a continuous model of the mechanical system (described with partial differential equations) by a discrete model expressed by a system of algebraic equations.

In order to obtain reliable modelling results, it is necessary to precisely determine elements of mass, damping and stiffness matrices, which describe the machine (Uhl, 1997). While the modelling of dynamical properties of machine tool bodies is not a problem, modelling procedures for guides, transmission systems, etc., are still being built and improved. Chlebus and Dybala (Chlebus and Dybala, 1999) presented a method for modelling the stiffness of sliding guides using the finite element method. The authors introduced the concept of the "third body", which allowed modelling of phenomena occurring in the contact layer of sliding connections. Szwengier et al. (2000) proposed a method to improve the accuracy of analytical models of machine tool load-bearing systems based on the results obtained from experimental research. The analytical model of the structure built in accordance with the concept of the rigid finite element method was enriched with the modelling of contact phenomena in accordance with the concept of external load correction. The modelling of power transmission systems was presented comprehensively by (Altintas et al., 2011; Ebrahimi and Whalley, 2000; Erkorkmaz and Altintas, 2001). Zaeh et al. (2004) presented the methodology of modelling ball-screw mechanisms, adapted for use in commercial computation packages, based on the finite element method. A solution was presented to enable the application of the ball-screw mechanism model in the model of the entire machine tool. Zhang et al. (2016) presented an equivalent model of the ball-screw mechanism based on the assumption that the equivalent stiffness of that connection depended on the axial stiffness of the connection between the screw and the nut, the stiffness of the load-bearing system and the torsional stiffness of the ball screw.

However, the choice of the modelling method becomes irrelevant if one does not have results of experimental studies to validate the method. Achieving satisfactory accuracy of models of such complex dynamic structures as a machine tool without the use of identification procedures is extremely difficult.

This article presents the results of modelling a machine tool in the convention of the finite element method using simplified models of driving system components compared with the results of experimental modal analysis. The proposed simplification does not affect model accuracy while shortens computational time. Compatibility of the simplified model with the results of the experiment (both in terms of mode shapes and frequency response functions) and the usefulness of the presented approach in the diagnosis of stability loss during the milling process is presented, which is a novel part of this work.

The research problem and the object of research are presented in detail in Section 2. Section 3 presents the process of building a machine tool model using equivalent models of stiffness of transmission systems. Section 4 presents the results of the process of identifying the computational model based on the results of experimental model analysis. Section 5 contains a proposal of design modifications aimed at counteracting the loss of machining stability.

\section{Research object, examinations under operating conditions}

The object of the research was a prototype of the FNE-40 milling machine (Fig. 1) whose load-bearing system was modified in relation to earlier versions of the machine tool in order to increase its machining space. The modification consisted in shortening length of the support 
of the guide system of the sliding overarm (marked in gold in Fig. 1). These activities were undertaken without any prior model tests.
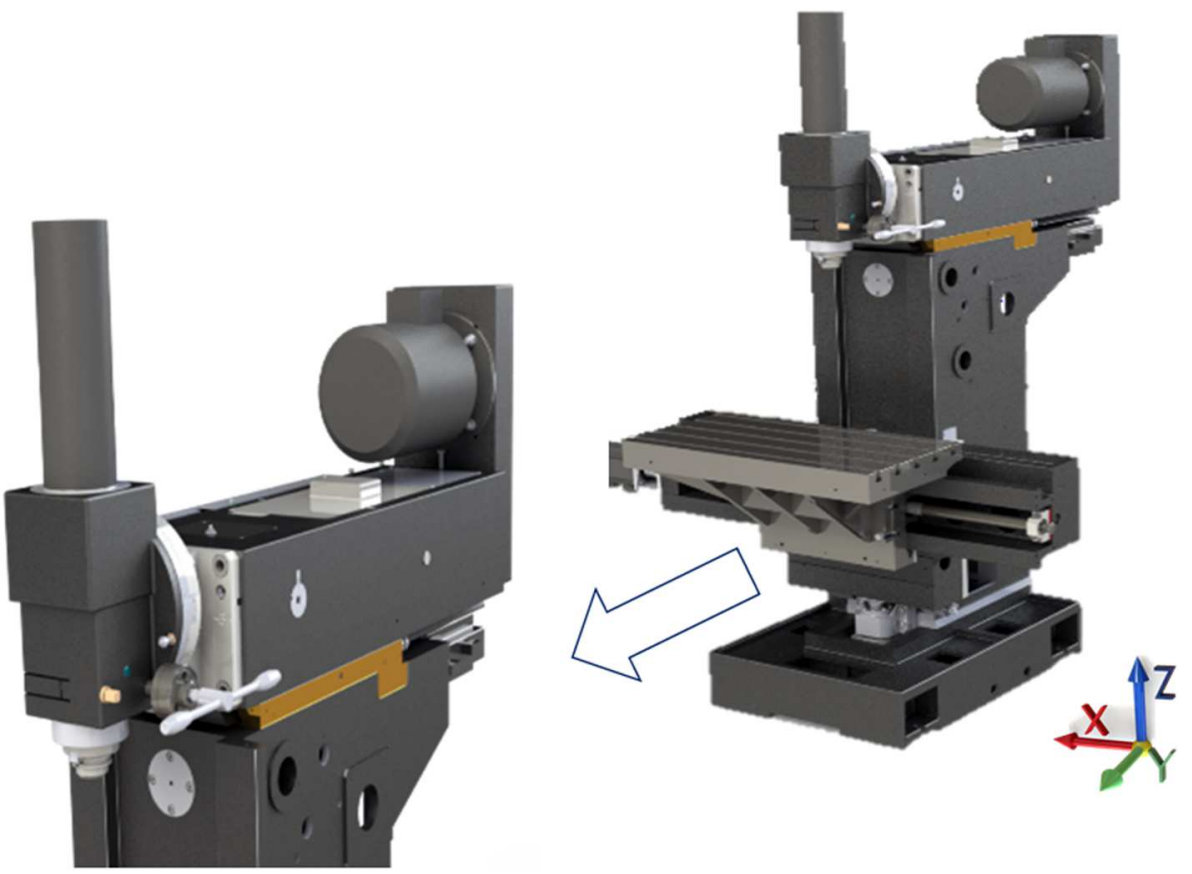

Fig. 1. General view of the prototype of the tested milling machine with the selection of the modified element

The introduced structural changes significantly reduced the machine operational properties, which, moreover, began to show symptoms of loss of machining stability. In order to identify the nature of generated vibrations and indicate the type of remedial actions, a diagnostic procedure consisting of several stages was carried out. In the first stage, the machining was realized under stable and unstable conditions (the evaluation was made on the basis of surface quality). At the same time, there were different levels of machining parameters, such as tool rotation speed, feed speed, and feed direction. Regardless of these modifications, a loss of stability was observed for even a small depth of cut (about $2 \mathrm{~mm}$ ) (Fig. 2).

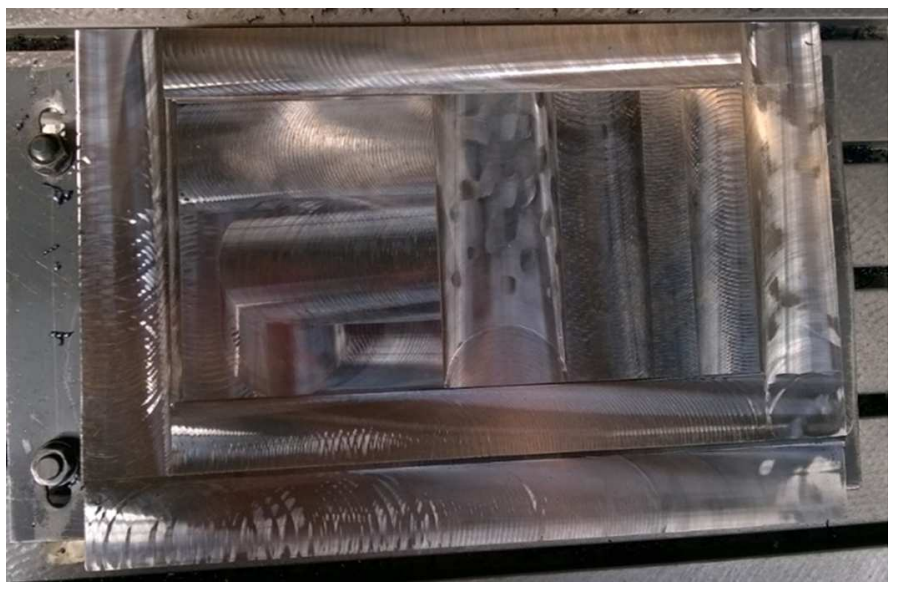

Fig. 2. View of the machined surface with marks of strong self-excited vibrations

Then, the acceleration signals measured during machining were analyzed. Signal spectra were determined and frequency components corresponding to tooth cutting into the material $(127.3 \mathrm{~Hz})$ and its harmonics were determined (Fig. 3). 


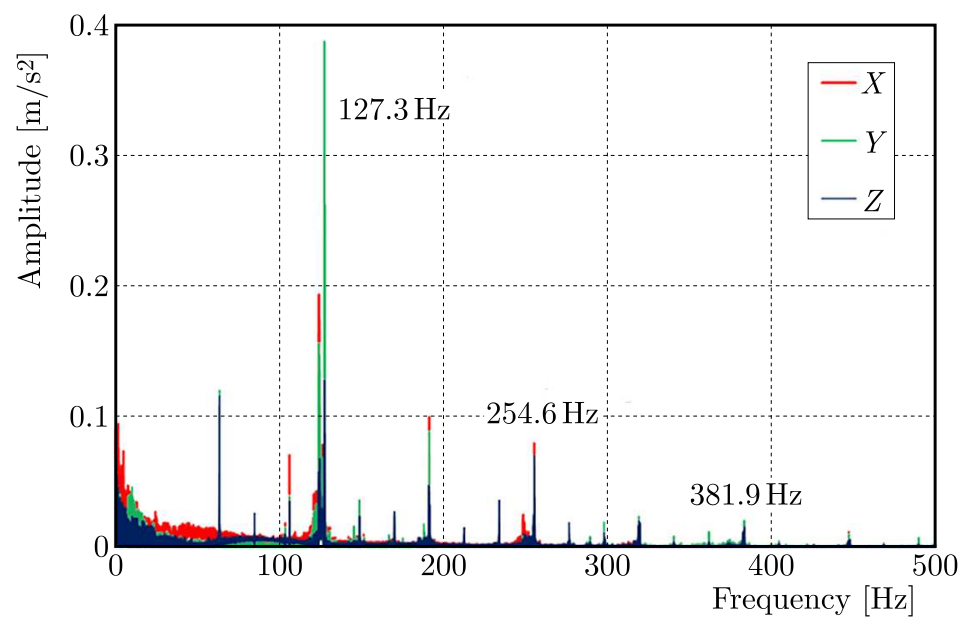

Fig. 3. An example of the spectrum of the acceleration signal measured during machining on the workpiece

There was no correlation between the rotational speed and the effect of loss of machining stability. Therefore, it was considered that the loss of machining stability was mainly caused by unfavorable coupling of mass-damper-spring properties resulting from the modification to the machine tool structure. Therefore, analysis focused on changes in the frequency composition of the acceleration signal recorded during machining using short-time Fourier transformation (STFT) (Oran Brigham, 1988; Tansel et al., 2006) for the displacement of the workpiece relative to the headstock in the $X$ direction (Fig. 4).

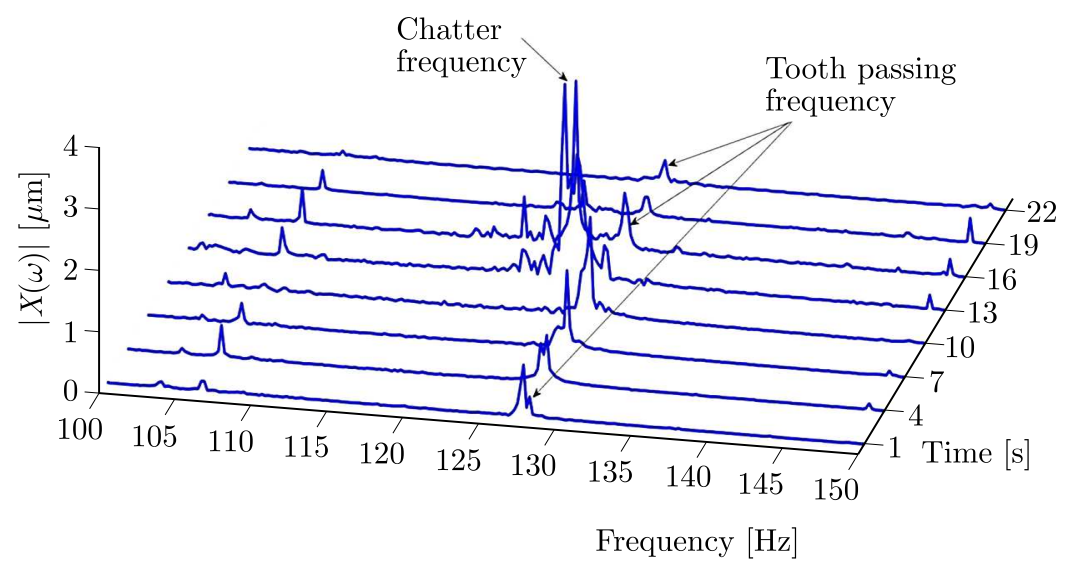

Fig. 4. Determination of the frequency of self-excited vibrations using STFT

The dominant amplitude of vibrations was determined at $124 \mathrm{~Hz}$ when machining stability was lost. It was not the cutting frequency of the cutting edge and it probably corresponded to one of the mode shapes of the whole structure. To prove this, model tests were carried out the aim of which was to identify the mode shape at a frequency close to $124 \mathrm{~Hz}$ and to indicate the elements of the machine tool structure characterized by significant vibrations close to that frequency - detection of the "weak link". This was carried out using the finite element method, and the model was verified based on the results of experimental model analysis.

\section{Construction of the FEM model}

The construction of the model in the convention of the finite element method began with defining the geometrical model, i.e. giving the structure appropriate dimensions and shapes, and selecting 
material constants. Necessary simplifications were made, comprising removing non-essential features in terms of the dynamical properties of the machine tool, i.e. small holes, small roundings, chamfers, etc. After preparing the geometric model, discretization was made using elements of the CHEXA and CTETRA type (Fig. 5).

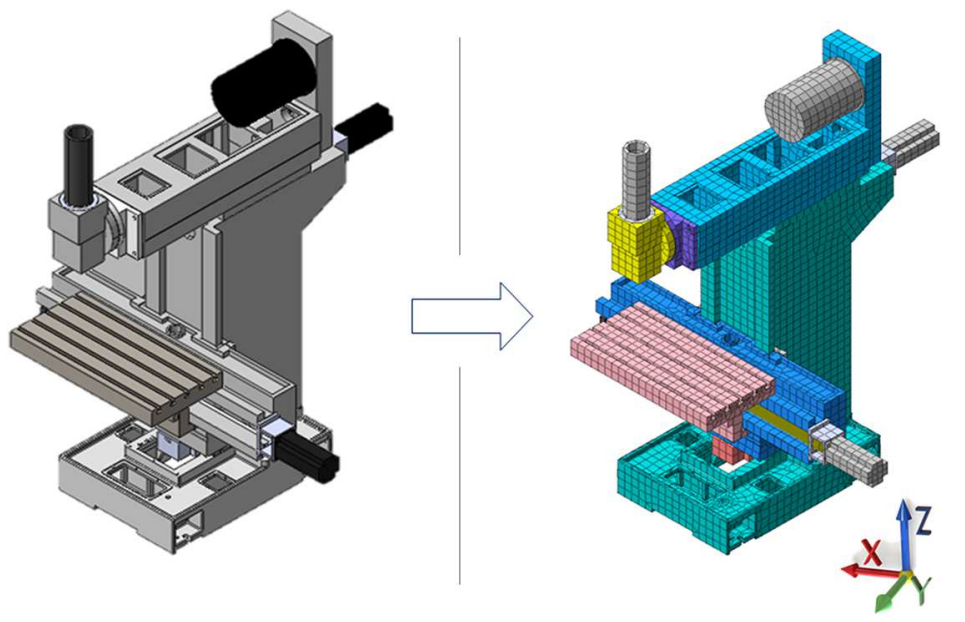

Fig. 5. Geometric model subjected to the process of discretization

Next, the stiffness of equivalent elements modelling the ball screw mechanisms was determined, considered as stiffness in the direction of the screw axis. Such simplification was consistent with the principles of constructing guide connections, in which the feed mechanism was loaded only with an axial force, whereas other construction elements such as roller guides or sliding guides were responsible for the load transfer in other directions (Altintas, 2012; Koenigsberger and Tlusty, 2016; Marchelek, 1991).

The equivalent stiffness of the connection between the cross slide with the support has been determined taking into account the stiffness of individual components of the ball screw

$$
\frac{1}{K_{t o t}}=\frac{1}{K_{s}}+\frac{1}{K_{n s}}+\frac{1}{K_{b}}+\frac{1}{K_{c}}
$$

where $K_{s}$ is the stiffness of the ball screw, $K_{n s}$ - stiffness of the screw-nut connection, $K_{b}$ - axial stiffness of the fixed bearing unit, $K_{c}$ - stiffness of the claw clutch, determined in accordance with the diagram shown in Fig. 6.
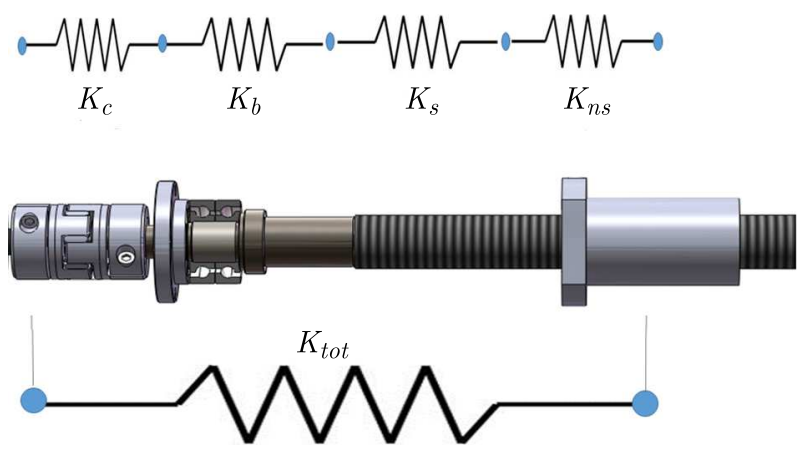

Fig. 6. Determination of the equivalent stiffness of the ball screw

In order to determine the stiffness of the screw, the following formula was used

$$
K_{s}=\frac{\pi \bar{d}^{2} E}{4 l \cdot 10^{3}}
$$


where $E$ is Young's modulus of the material, $l$ - length of the loaded portion of the screw between the fixed bearing and the nut, $\bar{d}$ - average diameter of the screw, calculated on the basis of the outside and inside diameters (Fig. 7)

$$
\bar{d}=\frac{d_{1}+d_{2}}{2}
$$

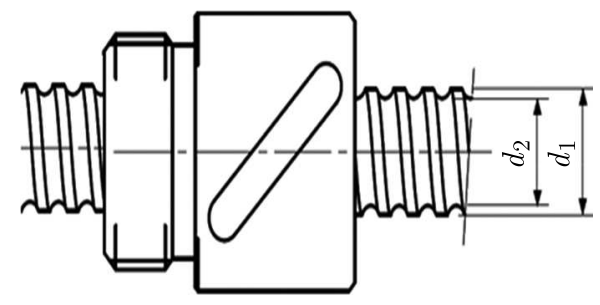

Fig. 7. Diameters of the ball screw

Next, the stiffness of the screw-nut connection was determined using the equation describing the normal stiffness in the case of a ball with two raceways (Dolata, 2015)

$$
K_{n s}=\frac{K_{n s_{i}} K_{n s_{o}}}{K_{n s_{i}}+K_{n s_{o}}}
$$

where $K_{n s_{i}}$ is the contact stiffness between the ball and the inner raceway, $K_{n s_{o}}$ - contact stiffness between the ball and the outer raceway. Values of $K_{n s_{i}}$ and $K_{n s_{o}}$ were determined based on the Hertz contact theory. The stiffness of the fixed bearing arrangement and the stiffness of the claw clutch were adopted on the basis of data provided by the manufacturers IBC Wälzlager and $\mathrm{R}+\mathrm{W}$, respectively.

Similarly, the equivalent stiffness was determined for the ball screw drive between the main body and the overarm, and between the main body and the knee. The claw clutch stiffness occurring in Eq. (3.1) was omitted. However, a new element was introduced - stiffness of the toothed belt $K_{b t}$

$$
\frac{1}{K_{t o t}}=\frac{1}{K_{s}}+\frac{1}{K_{n s}}+\frac{1}{K_{b}}+\frac{1}{K_{b t}}
$$

the stiffness $K_{b t}$ is expressed as follows

$$
K_{b t}=\frac{K_{b e}}{r} s
$$

where $K_{b e}$ is the tensile stiffness of the belt, $r$ - radius of the carriage attached to the ball screw, $s$ - pitch of the screw.

The stiffness of sliding guides in the normal direction was modeled using a contact surface-to-surface model for bidirectional sliding surfaces. The stiffness in the direction tangent to the sliding surfaces was modeled using the model presented by Dahl (1968), Dupont et al. (2002), Gutowski and Leus (2012), describing the value of the friction force depending on the elastic deformation in the contact area

$$
F_{f}=k_{t} z
$$

where $F_{f}$ is the friction force, $z$ - elastic deformation in the contact zone, $k_{t}$ - stiffness factor in the tangential direction

$$
k_{t}=\frac{F_{f}}{z}
$$


The damping of the structure was described by a complex stiffness; according to the adopted model, the stiffness matrix $\mathbf{K}^{*} \in M_{n}(\mathbb{C})$ has the form

$$
\mathbf{K}^{*}=(1+\mathrm{i} \eta) \mathbf{K}
$$

where $\mathbf{K}$ is the structure stiffness matrix, $\eta$ - loss coefficient, i - imaginary unit

$$
\eta=2 \zeta
$$

For the model prepared in this way, the mode shapes were obtained as a result of solving the eigenproblem presented in the following form

$$
\left(\mathbf{K}-\omega^{2} \mathbf{M}\right) \mathbf{w}=\mathbf{0}
$$

where $\mathbf{K}$ is the structure stiffness matrix (real part), $\mathbf{M}$ - structure inertia matrix, $\mathbf{w}$ - eigenvectors matrix, $\omega^{2}$ - eigenvalues matrix.

As a result of solving the formulated problem, a set of eigenvectors and eigenvalues was obtained. Figures 8, 9 and 10 present mode shapes from the point of view of loss of stability. The selection was made based on the proximity of eigenvalues to $124 \mathrm{~Hz}$ and the significance of displacements in the directions affecting changes in the cross-section of the cut.

Figure 8 shows the mode shape at a natural frequency of $76.4 \mathrm{~Hz}$. From the point of view of loss of stability, anti-phase motion of the knee-table system was noticed along the $X$ axis with respect to the overarm-headstock unit. This motion also influenced thickness of the cut.
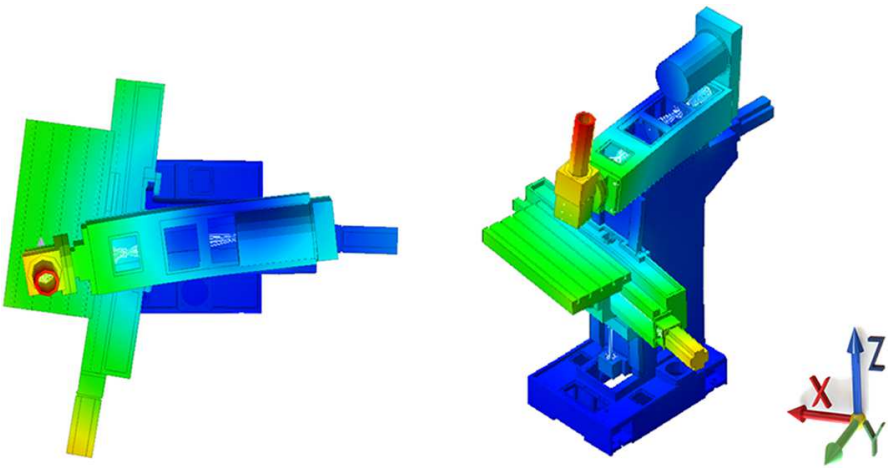

Fig. 8. Mode shape at $76.4 \mathrm{~Hz}$
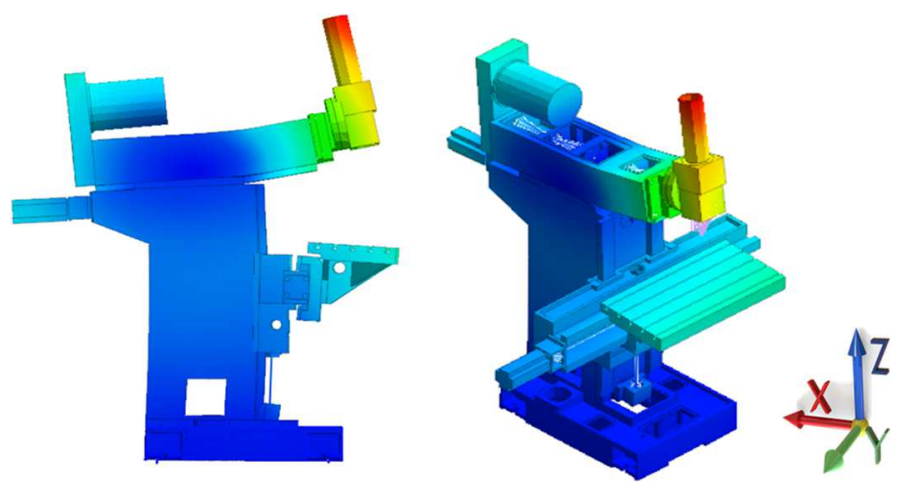

Fig. 9. Mode shape at $94.2 \mathrm{~Hz}$

Stability could have been equally significantly affected by the vibrations at $94.2 \mathrm{~Hz}$ shown in Fig. 9, characterized by clear vibrations of the headstock together with the overarm in the $Z$ axis. 
This movement significantly affected geometrical parameters of the cutting layer, especially depth of the cut.

Figure 10 shows vibrations characterized by the mutual movement of the knee-table unit relative to the overarm-headstock unit.
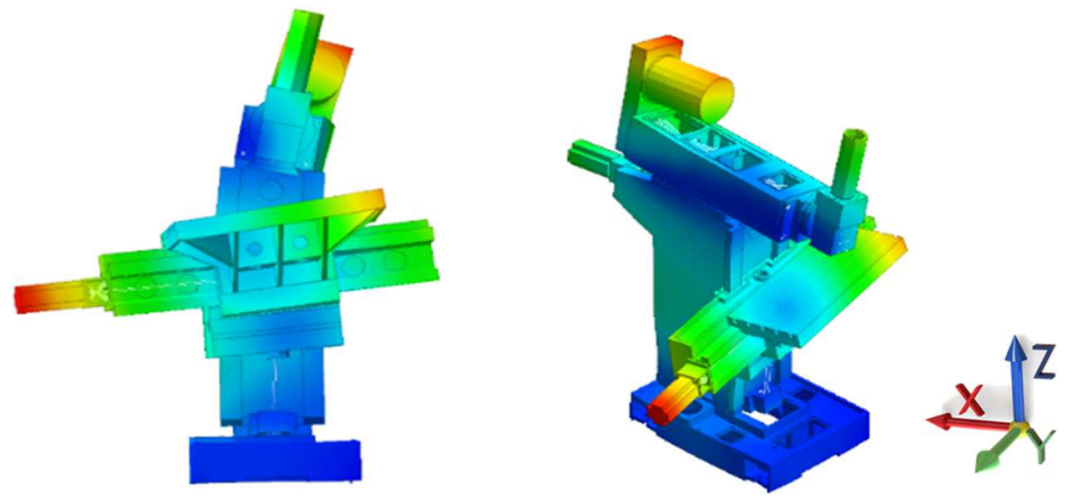

Fig. 10. Mode shape at $137.1 \mathrm{~Hz}$

A common feature of the presented mode shapes are clear vibrations of the overarm. To ensure that the conclusions were correct and confirmed the indication of the weak link responsible for the loss of machining stability, a research program was implemented to validate the computed model.

\section{Identification of the FEM model}

In order to identify the FEM model, an experiment was carried out in the form of an impulse test. The dynamic response of the machine tool was measured in the locations selected based on analysis of the mode shapes obtained as a result of solving the eigenproblem of the FEM model. Excitation was applied in three orthogonal directions by the modal hammer in accordance with the machine axes. The scheme of the experimental setup is shown in Fig. 11.

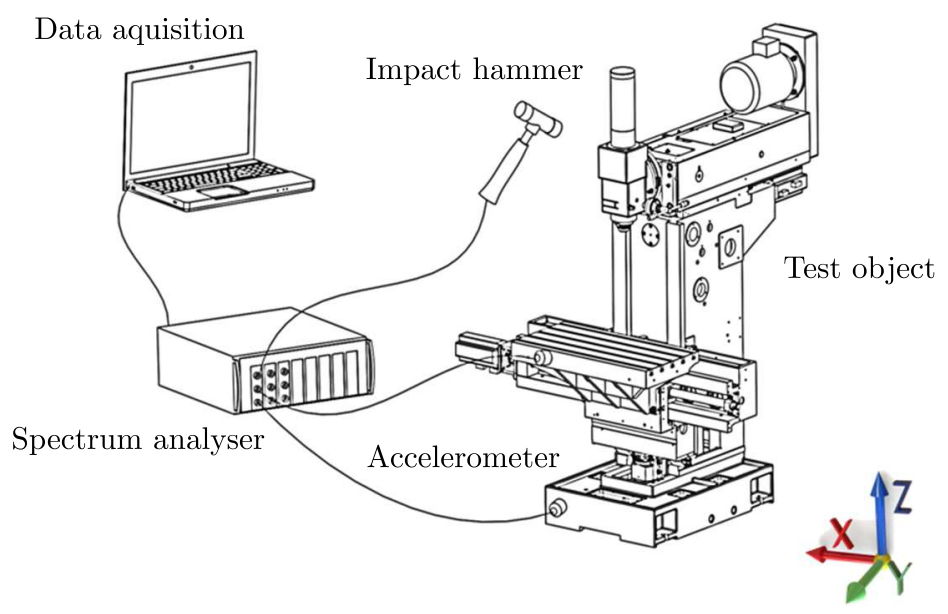

Fig. 11. Diagram of the experimental setup

The experiment consisted of preliminary activities, such as temperature stabilization of research equipment, determination of signal acquisition and processing parameters: sensitivity of acceleration sensors was about $10 \mathrm{mV} /\left(\mathrm{m} / \mathrm{s}^{2}\right)$, frequency resolution $1 \mathrm{~Hz}$, estimator of the frequency response function $H 1$. The entire study was carried out using the SCADAS III measuring system operating under control of the LMS TestLab system. The Polymax algorithm was used 
to estimate the parameters of the modal model. The correctness of the choice of stabilizing poles was evaluated on the basis of modal assurance criterion (MAC). The modal model of the machine tool, in the form of frequency and modal damping, is presented in Table 1, comparing it with the results obtained from the FEM model analysis. The bold font denotes vibrations that are significant from the point of view of the loss of machining stability.

Table 1. The modal model of the FNE-40 milling machine

\begin{tabular}{|c|c|c|}
\hline Mode shape & Experimental model & FEM model \\
\hline \hline 1 & $14.422 \mathrm{~Hz}, 2.20 \%$ & $18.1 \mathrm{~Hz}$ \\
\hline 2 & $19.292 \mathrm{~Hz}, 1.72 \%$ & $21.7 \mathrm{~Hz}$ \\
\hline 3 & $37.352 \mathrm{~Hz}, 2.47 \%$ & $42.5 \mathrm{~Hz}$ \\
\hline 4 & $67.510 \mathrm{~Hz}, 5.36 \%$ & $76.4 \mathrm{~Hz}$ \\
\hline 5 & $73.158 \mathrm{~Hz}, 2.43 \%$ & $77.9 \mathrm{~Hz}$ \\
\hline 6 & $87.619 \mathrm{~Hz}, 0.43 \%$ & $94.2 \mathrm{~Hz}$ \\
\hline 7 & $105.714 \mathrm{~Hz}, 3.76 \%$ & - \\
\hline 8 & $126.021 \mathrm{~Hz}, 2.98 \%$ & $137.1 \mathrm{~Hz}$ \\
\hline 9 & $128.854 \mathrm{~Hz}, 1.13 \%$ & $143.8 \mathrm{~Hz}$ \\
\hline 10 & $141.462 \mathrm{~Hz}, 3.53 \%$ & $148.6 \mathrm{~Hz}$ \\
\hline
\end{tabular}

In the next step, animations of mode shapes were constructed and comparisons were made between the vibrations obtained in the experimental and finite element methods. A comparison of selected figures is shown in Figs. 12-14.

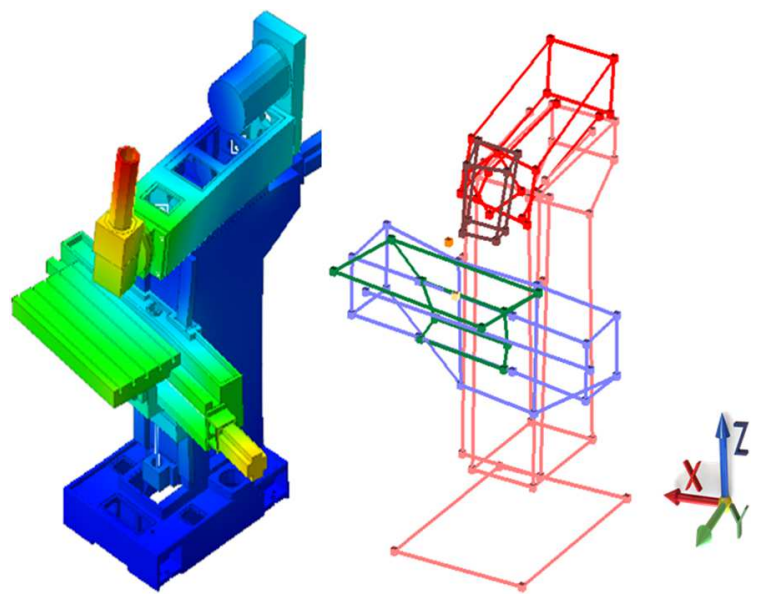

Fig. 12. Comparison of mode shape No. 5 determined by the FEM model and experimentally

Figures 15 and 16 show experimentally (marked in red) and analytically (marked in blue) designated frequency response functions in the representative locations in the structure - the headstock and the table, showing their convergence.

Analysis of the data contained in Table 1 indicates some discrepancies between the computational and experimental models. The FEM model did not reproduce No. 7 vibrations shown in Fig. 17. Difficulties associated with the a priori identification of this mode shape were associated with errors from the assembly that were not included in the model. In the case of this mode shape, the "weak link" was the connection between the overarm and the headstock.

The intermediate element highlighted in Fig. 18 moved in phase with the headstock, despite the fact the method of fixing should have made it move together with the overarm. This behavior of the structure indicated insufficient stiffness of the connection, which would then have resulted in the loss of stability of the milling process. Importantly, the modification made by 

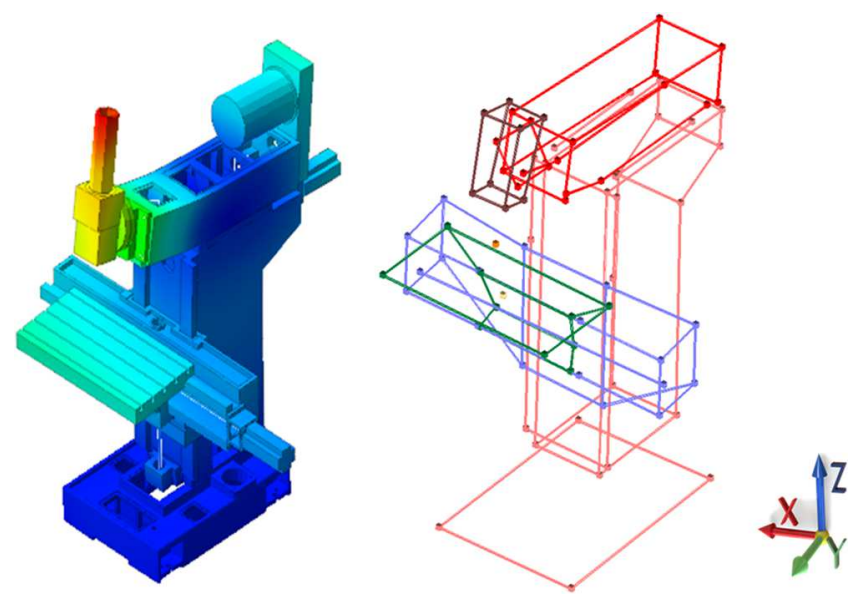

Fig. 13. Comparison of mode shape No. 6 determined by the FEM model and experimentally
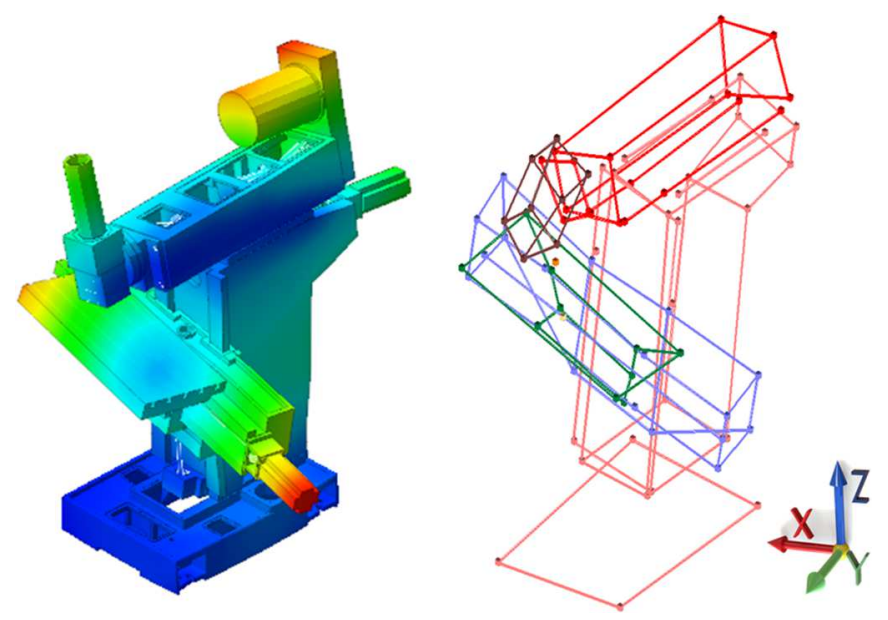

Fig. 14. Comparison of mode shape No. 8 determined by the FEM model and experimentally

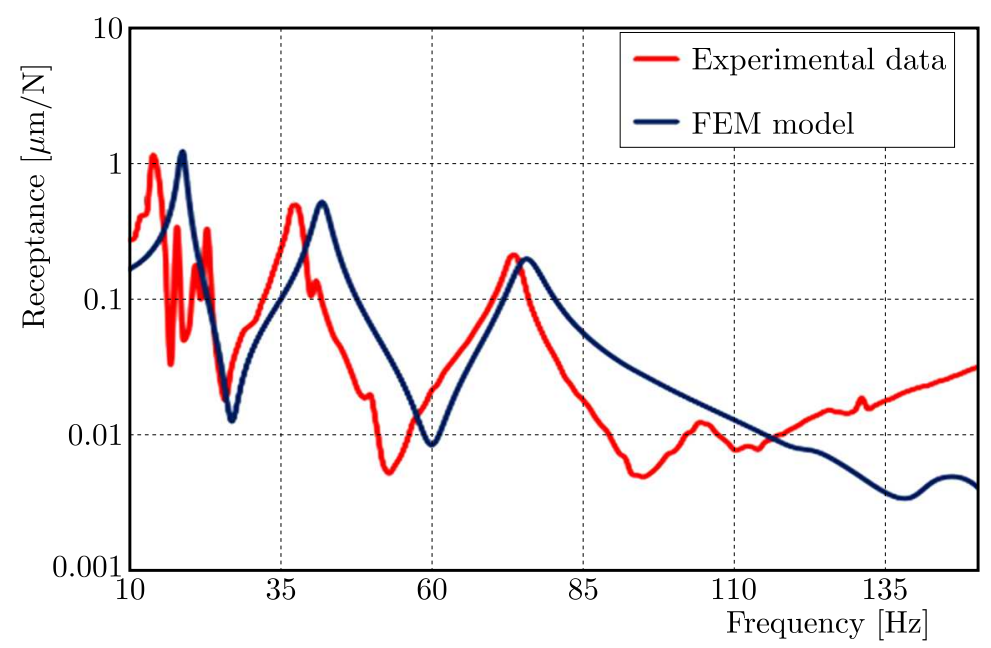

Fig. 15. Comparison of the frequency response functions for the headstock in the $X$ axis

the manufacturer did not apply to this element, and the assembly technology did not change. Therefore, the change in the dynamic properties of one of the sliding connections of the machine tool caused "activation" of another connection, resulting in an unfavorable combination of these properties and, as a result, the loss of machining stability. 


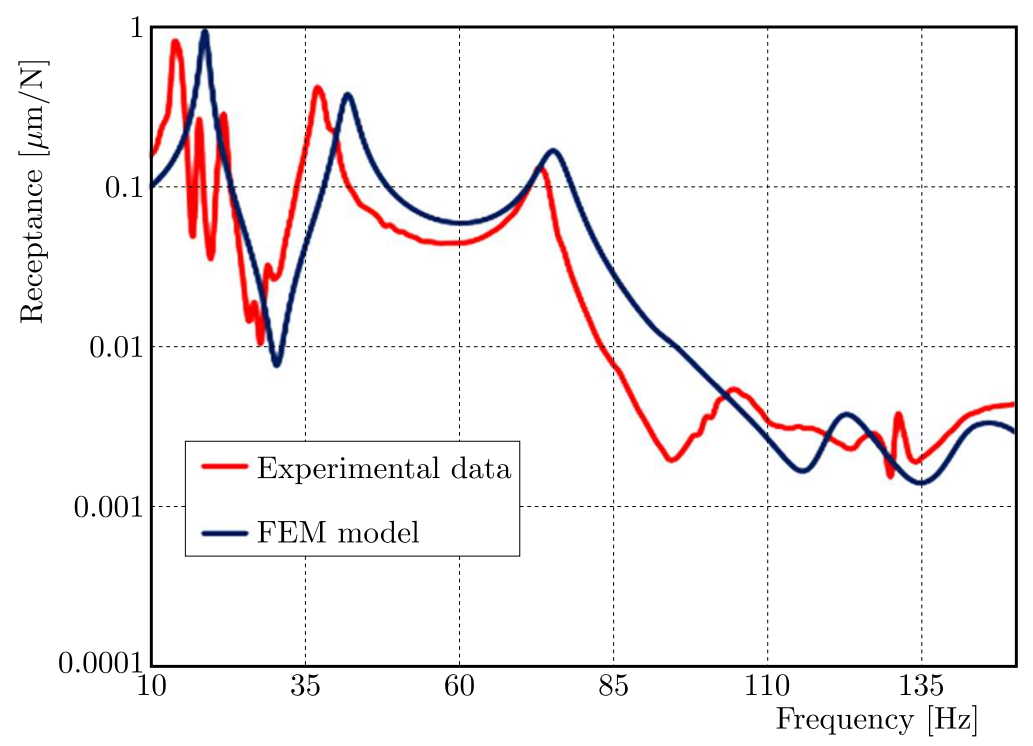

Fig. 16. Comparison of frequency response functions for the table in the $X$ axis
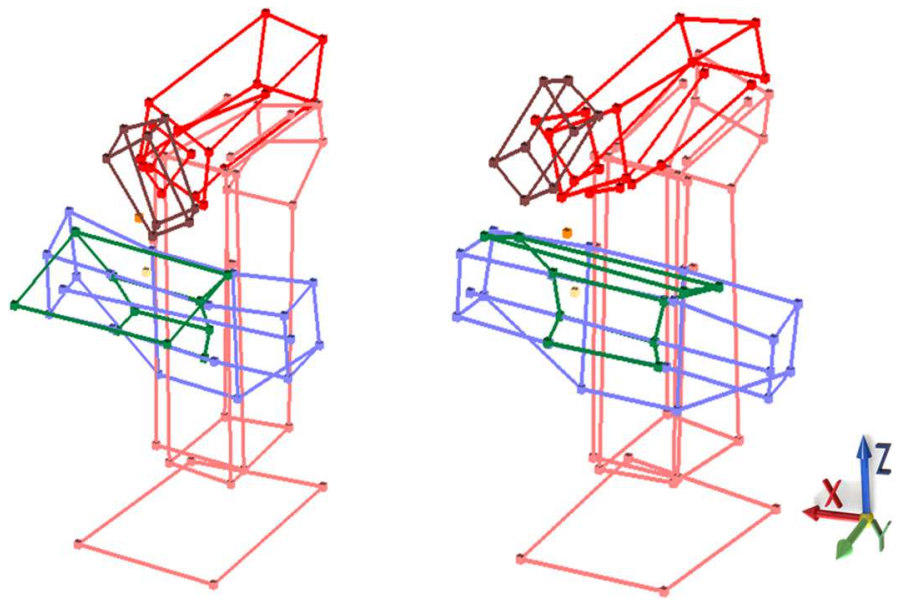

Fig. 17. Mode shape $105.714 \mathrm{~Hz}$ related do the weak link

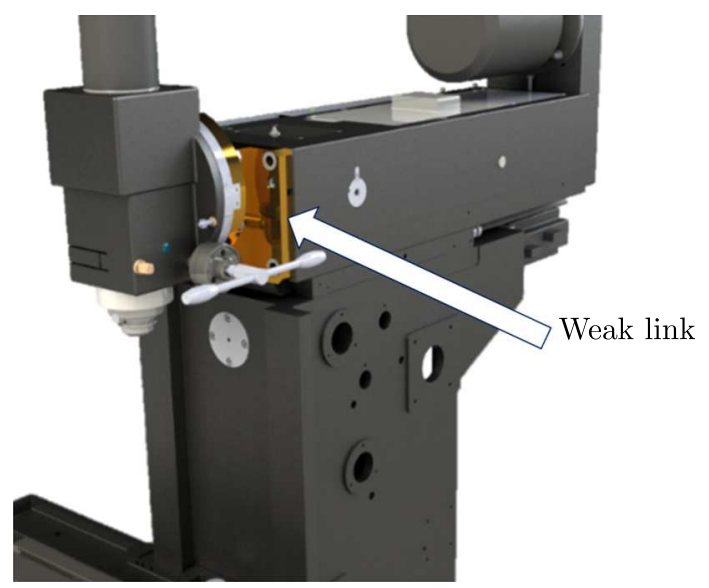

Fig. 18. The element responsible for the loss of machining stability 
Detailed analysis of mode shapes animation combined with a comparison of amplitude levels of the frequency response functions at selected points of the model allowed us to formulate the following guidelines regarding structural changes:

- the stiffness of the connection between the headstock and the overarm should be increased;

- the ribbing system inside the overarm should be modified to increase its stiffness in the $Z$ axis.

The first recommendation was fulfilled by changing the assembly technology of these elements and increasing the contact surface adherence accuracy. The implementation of the second recommendation, requiring a broader discussion, is presented in Section 5.

\section{Modification of construction}

The initially introduced structural change consisting of shortening length of the bracket of the sliding guide system of the sliding overarm caused a change in the spatial relationship between length of the guide and the distribution of ribs inside the overarm. As a result, significant levels of vibration amplitudes were observed in the vertical $Z$ axis. Those were not directly the cause of the loss of stability, but because of the direction of action they negatively affected the accuracy of machining.

In order to determine the optimum ribbing distribution for the stiffness in the $Z$ direction, model tests were carried out using the finite element method. The identified machine model was used for these tests.

As a result, a new arrangement of the overarm ribbing was proposed, resulting in a significant reduction of the amplitude of vibrations in the $Z$ axis of the machine. Figure 19a shows the original arrangement of the ribs, and Fig. 19b shows ribbing modified to increase the stiffness.
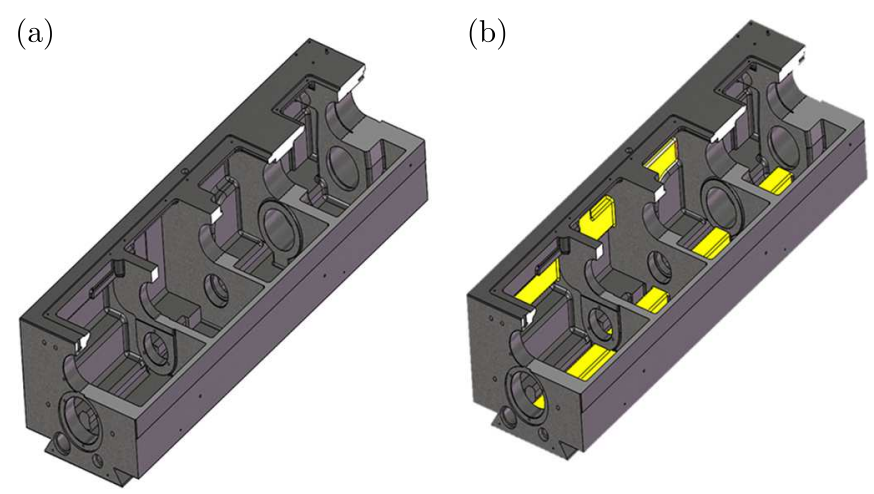

Fig. 19. Distribution of overarm ribbing (a) before modification, (b) after modification

The indicated structural changes were implemented in production, positively affecting the machine operational properties.

\section{Conclusion}

The implementation of the test procedure described in the article resulted in the intended effect, i.e. elimination of the loss of machining stability. It was also shown that changes made to the machine tool structure, carried out without an appropriate research model, could lead to negative effects. In addition, changes in the properties of one connection can affect "activation" of a completely different structure element of the machine tool and formation of a weak link. 


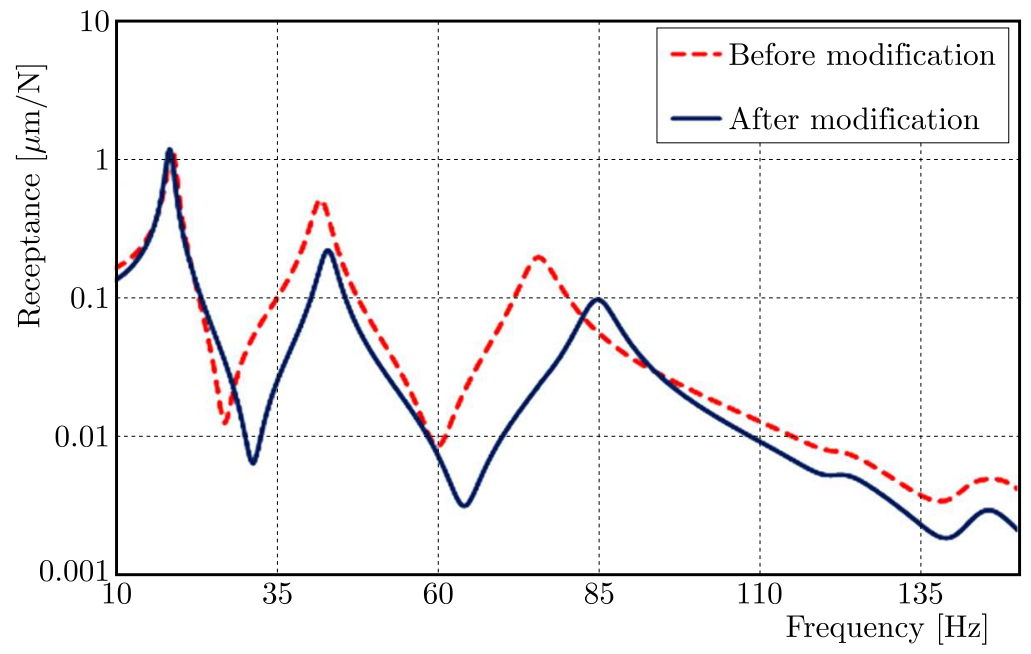

Fig. 20. Comparison of selected dynamic compliance functions before introducing modifications to increase stiffness and again after their application

This study showed that the modelling using deformable finite elements requires implementation of a validation procedure based on the results of experimental research. The experimental model analysis is a great tool to achieve this goal. It allows identification of the so-called weak link, which is the effect of, for example, inappropriate assembly. Such features are not modeled a priori in FEM systems before providing information about the possibility of such a disadvantage.

\section{References}

1. Altintas Y., 2012, Manufacturing Automation: Metal Cutting Mechanics, Machine Tool Vibrations, and CNC Design, Cambridge University Press

2. Altintas Y., Brecher C., Weck M., Witt S., 2005, Virtual machine tool, CIRP Annals-Manufacturing Technology, 54, 2, 115-138

3. Altintas Y., Veri A.W., Brecher C., Uriarte L., Pritschow G., 2011, Machine tool feed drives, CIRP Annals-Manufacturing Technology, 60, 2, 779-796

4. Berczynski S., Lachowicz M., Pajor M., 2001, An improved method of approximating frequency characteristics in the problem of modal analysis and its applications, WIT Transactions on Modelling and Simulation, 30

5. CAo H., Lei Y., He Z., 2013, Chatter identification in end milling process using wavelet packets and Hilbert-Huang transform, International Journal of Machine Tools and Manufacture, 69, 11-19

6. Chlebus E., Dybala B., 1999, Modelling and calculation of properties of sliding guideways, International Journal of Machine Tools and Manufacture, 39, 12, 1823-1839

7. ChodźKo M., 2015, The search for weak elements affecting the vibrostability of the system consisting of the machine tool and the cutting process, based on symptoms observed during operation, Problemy Eksploatacji, 1, 5-23

8. Chodźko M., Pajor M., 2016. Static and dynamic properties examination of R1000 milling machine prototype, Advances in Manufacturing Science and Technology, 40, 4

9. Dahl P.R., 1968, A Solid Friction Model, Aerospace Corporation, El. Segundo, CA

10. Dolata M., 2015, Model of roller screw and its experimental verification (in Polish), PhD Thessis, West Pomeranian University of Technology Szczecin, Szczecin 
11. Dombovari Z., Barton D.A.W., Wilson R.E., Stepan G., 2011, On the global dynamics of chatter in the orthogonal cutting model, International Journal of Non-Linear Mechanics, 46, 1, 330-338

12. Dunaj P., Chodźko M., 2017, Experimental investigation on dynamic properties of turning machine, Advances in Manufacturing Science and Technology, 41, 1, 21-29

13. Dupont P., Hayward V., Armstrong B., Altpeter F., 2002, Single state elastoplastic friction models, IEEE Transactions on Automatic Control, 47, 5, 787-792

14. Ebrahimi M., Whalley R., 2000, Analysis, modelling and simulation of stiffness in machine tool drives, Computers and Industrial Engineering, 38, 1, 93-105

15. Erkorkmaz K., Altintas Y., 2001, High speed CNC system design. Part II: modelling and identification of feed drives, International Journal of Machine Tools and Manufacture, 41, 10, 1487-1509

16. Faassen R.P.H., van de Wouw N., Oosterling J.A.J., Nijmeijer H., 2003, Prediction of regenerative chatter by modelling and analysis of high-speed milling, International Journal of Machine Tools and Manufacture, 43, 14, 1437-1446

17. Gradišek J., Kalveram M., Insperger T., Weinert K., Stépán G., Govekar E., Grabec I., 2005, On stability prediction for milling, International Journal of Machine Tools and Manufacture, 45, 7-8, 769-781

18. Gutowski P., Leus M., 2012, The effect of longitudinal tangential vibrations on friction and driving forces in sliding motion, Tribology International, 55, 108-118

19. Hayasaka T., Atsushi I., Shamoto E., 2017, Generalized design method of highly-varied-helix end mills for suppression of regenerative chatter in peripheral milling, Precision Engineering, 48, $45-59$

20. Jafarzadeh E., Movahhedy R.M., 2017, Numerical simulation of interaction of mode-coupling and regenerative chatter in machining, Journal of Manufacturing Processes, 27, 252-260

21. Jasiewicz M., PowaŁka B., 2018a, Identification of a lathe spindle dynamics using extended inverse receptance coupling, ASME Journal of Dynamic Systems, Measurment and Control, 140, 12,121015

22. Jasiewicz M., PowaŁka, B., 2018b, Prediction of turning stability using receptance coupling, AIP Conference Proceedings, 1922, 1

23. JastrzęBSki D., 2008, Application of the hybrid finite elements method in modelling of static properties of machine tools load-carrying subsystems, Advances in Manufacturing Science and Technology, 32, 2, 5-20

24. Jastrzębski D., Dolata M., 2015, Modelling the carrying system of the machine tool under the condition of variable configurations of its motion units, Advances in Manufacturing Science and Technology, 39, 3

25. Koenigsberger F., Tlusty J., 2016, Machine Tool Structures, Elsevier

26. Kuljanic E., Sortino M., Totis G., 2008, Multisensor approaches for chatter detection in milling, Journal of Sound and Vibration, 312, 4-5, 672-693

27. Liu C., Zhu L., Ni C., 2018, Chatter detection in milling process based on VMD and energy entropy, Mechanical Systems and Signal Processing, 105, 169-182

28. Marchelek K., 1991, Machine Tool Dynamics (in Polish), Wydawnictwa Naukowo-Techniczne, Warszawa

29. Marchelek K., Pajor M., PowaŁka B., 2002, Vibrostability of the milling process described by the time-variable parameter model, Modal Analysis, 8, 4, 467-479

30. Munoa J., Beudaert X., Dombovari Z., Altintas Y., Budak E., Brecher C., Stépán G., 2016, Chatter suppression techniques in metal cutting, CIRP Annals, 65, 2, 785-808 
31. Oran Brigham E., 1988, The Fast Fourier Transform and Its Applications, Englewood Cliffs, NJ Prentice Hall

32. Pulikowski D., Lackner F., Scheuerlein Ch., Meinel D., Savary F., Tommasini D., PAJOR M., 2017, Testing mechanical behavior of $\mathrm{Nb}_{3} \mathrm{Sn}$ Rutherford cable during coil winding, IEEE Transactions on Applied Superconductivity, 27, 4, 1-5

33. Rusinek R., Lajmert P., Kecik K., Kruszynski B., Warminski J., 2015, Chatter identification methods on the basis of time series measured during titanium superalloy milling, International Journal of Mechanical Sciences, 99, 196-207

34. Rusinek R., Wiercigroch M., Wahi P., 2014, Modelling of frictional chatter in metal cutting, International Journal of Mechanical Sciences, 89, 167-176

35. Suzuki N., Ishiguro R., Kojima T., 2016, Design of irregular pitch end mills to attain robust suppression of regenerative chatter, CIRP Annals-Manufacturing Technology, 65, 1, 129-132

36. Szwengier G., Goduński T., Berczyński S., 2000, Identification of physical parameters in contact joints models of machines supporting systems, Advances in Engineering Software, 31, 2, $149-155$

37. Tansel I.N., Wang X., Chen P., Yenilmez A., Ozcelik B., 2006, Transformations in machining. Part 2. Evaluation of machining quality and detection of chatter in turning by using s-transformation, International Journal of Machine Tools and Manufacture, 46, 1, 43-50

38. Tlusty J., 1983, Special aspects of chatter in milling, Journal of Vibration, Acoustics, Stress, and Reliability in Design, 105, 1, 24-32

39. Tlusty J., PolaceK M., 1963, The stability of machine tools against self-excited vibrations in machining, International Research in Production Engineering, ASME, 465-474

40. Tomków J., 1997, Machine Tool Stability (in Polish), Wydawnictwa Naukowo-Techniczne, Warszawa

41. Uhl T., 1997, CAD CAM Computer Support. Computer-Aided Identification of Mechanical Structures Models (in Polish), Wydawnictwa Naukowo-Techniczne, Warszawa

42. Wiercigroch M., Krivtsov A.M., 2001, Frictional chatter in orthogonal metal cutting, Philosophical Transactions of the Royal Society of London A: Mathematical, Physical and Engineering Sciences, 359, 1781, 713-738

43. Wittbrodt E., Adamiec-Wójcik I., Wojciech S., 2007, Dynamics of Flexible Multibody Systems: Rigid Finite Element Method, Springer Science \& Business Media

44. Yao Z., Mei D., Chen Z., 2010, On-line chatter detection and identification based on wavelet and support vector machine, Journal of Materials Processing Technology, 210, 5, 713-719

45. ZAEH M., SiEdL D., 2007, A new method for simulation of machining performance by integrating finite element and multi-body simulation for machine tools, CIRP Annals-Manufacturing Technology, 56, 1, 383-386

46. Zaeh M.F., Oertli Th., Milberg J., 2004, Finite element modelling of ball screw feed drive systems, CIRP Annals-Manufacturing Technology, 53, 1, 289-292

47. Zhang J., Zhang H., Du C., Zhao W., 2016, Research on the dynamics of ball screw feed system with high acceleration, International Journal of Machine Tools and Manufacture, 111, 9-16

48. Zienkiewicz O.C., Taylor R.L., 1977, The Finite Element Method, Vol. 3, London McGraw-Hill 